\title{
Plasminogen activator inhibitor-1 in kidney pathology (Review)
}

\author{
SYLWIA MAŁGORZEWICZ ${ }^{1}$, EWA SKRZYPCZAK-JANKUN ${ }^{3}$ and JERZY JANKUN ${ }^{1-3}$ \\ ${ }^{1}$ Department of Clinical Nutrition, Medical University of Gdańsk, Gdańsk 80-211, Poland; ${ }^{2}$ Protein Research Chair, \\ Department of Biochemistry, College of Sciences, King Saud University, Riyadh 11451, Kingdom of Saudi Arabia; \\ ${ }^{3}$ Urology Research Center, Department of Urology, College of Medicine, University of Toledo, Toledo, OH 43614, USA
}

Received September 17, 2012; Accepted November 9, 2012

DOI: $10.3892 /$ ijmm.2013.1234

\begin{abstract}
Plasminogen activator inhibitor type-1 (PAI-1) inhibits tissue plasminogen activator (tPA) and urokinase plasminogen activator (uPA), which convert plasminogen to plasmin, a strong proteolytic enzyme. Thus, PAI-1 is a primary and negative regulator of plasmin-driven proteolysis. In addition to its main role as an inhibitor of fibrinolysis, PAI-1 has been implicated as a mediator in other processes, including fibrosis, rheumatoid arthritis, atherosclerosis, tumor angiogenesis and bacterial infections. It also significantly modulates cellular adhesion or migration, wound healing, angiogenesis and tumor cell metastasis. However, in the present study, we have reviewed the literature in relation to different kidney diseases where PAI-1 regulates fibrinolysis and acts independently of proteolysis. PAI-1 is normally produced in trace amounts in healthy kidneys but is synthesized in a wide variety of both acute and chronic diseased kidneys. We reviewed the role of PAI-1 in diabetic kidney nephropathy, chronic kidney disease, hemodialysis, peritoneal dialysis and in kidney transplantation. Increased PAI-1 expression results in accumulation of extracellular matrix (ECM) leading to numerous kidney diseases. Predisposition to some diseases is due to the genetic role of PAI-1 in their development. A number of studies demonstrated that the inhibition of PAI-1 activity or therapy with a mutant PAI-1 increases matrix turnover and reduces glomerulosclerosis by competing with endogenous PAI-1. This strongly suggests that PAI-1 is a valid target in the treatment of fibrotic renal disease. However, net proteolytic activity depends on the delicate balance between its negative regulation by PAI-1 and activation by uPA and tPA. Also, plasmin activated by its inhibitors upregulates activity of other enzymes. Thus, assessment of prognosis for the diseased kidney should include a variety of proteolysis regulators and enzymes.
\end{abstract}

Correspondence to: Professor Jerzy Jankun, Urology Research Center, Department of Urology, College of Medicine, University of Toledo, 3000 Arlington Avenue, Toledo, OH 43614, USA

E-mail: jerzy.jankun@utoledo.edu

Key words: kidney, plasminogen activator inhibitor, kidney disease

\section{Contents}

1. Introduction

2. PAI-1 in kidney transplantation

3. PAI-1 in diabetic kidney nephropathy

4. PAI-1 in chronic kidney disease

5. Hemodialysis and PAI-1

6. Peritoneal dialysis and PAI-1

7. Conclusions

\section{Introduction}

The kidney plays a critical role in human health and failure in glomerular filtration leads to severe handicap and mortality unless the diseased kidney is replaced by transplantation. Kidney diseases often accompany diabetes and obesity. These two ailments are also interrelated with cardiovascular (CV) risk and deep vein thrombosis. The above suggest involvement of proteolytic enzymes of fibrinolysis. In this review, we have focused on plasminogen activator inhibitor type-1 (PAI-1), a potent regulator of fibrinolysis.

PAI-1 inhibits tissue plasminogen activator (tPA) and urokinase plasminogen activator (uPA). These two convert plasminogen to plasmin, a strong proteolytic enzyme. Therefore, PAI-1 is a primary and negative regulator of plasmin-driven proteolysis (1-3). PAI-1 is involved in several biological processes, and, depending on the disease, its overexpression or deficiency may trigger unexpected outcomes. For example, patients with PAI-1 deficiency (defined as activity of PAI-1 in blood lower than $1 \mathrm{IU} / \mathrm{ml}$ ) suffer from frequent bleeding episodes. This is a result of a premature clot lysis by overproduction of plasmin (4-6). Hereditary PAI-1 deficiency is caused by variants of PAI-1 Ala15Thr, Val17Ile resulting from polymorphisms at a signal peptide (7) and frame-shift mutation in exon 4 of the PAI-1 gene that resulted in complete PAI-1 deficiency due to nonfunctional protein (4). By contrast, hyperactivity of PAI-1 has been associated with an increased risk for coronary artery disease and myocardial infarction due to inhibition of fibrinolysis (8-10). A common functional deletion/insertion polymorphism $(4 \mathrm{G} / 5 \mathrm{G})$ in the promoter region of the PAI-1 gene located at $675 \mathrm{bp}$ was reported to result in the enhanced plasma expression of PAI-1 (11).

In addition to its major role as an inhibitor of fibrinolysis, PAI-1 has been implicated as a mediator in other processes, 
including fibrosis, rheumatoid arthritis, atherosclerosis, tumor angiogenesis and bacterial infections. It also significantly modulates cellular adhesion or migration, wound healing, angiogenesis, and tumor cell metastasis (12-14). However, in the present study, we have reviewed literature in relation to different kidney diseases where PAI-1 regulates fibrinolysis and acts independently of proteolysis. PAI-1 is normally produced in trace amounts in healthy kidneys but is synthesized in a wide variety of both acute and chronic diseased kidneys $(15,16)$.

\section{PAI-1 in kidney transplantation}

Steady improvements in patient first-year and graft survival rates have been reported by Rerolle et al (17). Nevertheless, chronic allograft dysfunction (CAD) remains the leading cause of the late renal allograft loss. Thus, numerous investigators have attempted to decifer the mechanism of renal kidney transplant failure.

Persistent fibrin accumulation has been observed in kidney chronic rejection. The process to remove fibrin in tissues is initiated by tPA and suppressed by PAI-1. For that reason, Wang et al (18) investigated their roles in chronic rejection and fibrin deposition in a Fisher 344 to Lewis rat renal transplant model. The authors examined the expression of tPA and PAI-1 in a chronic rejection model at $0,2,4,6,10,12,16$ and 20 weeks post-transplantation. They found that tPA was overexpressed only in the acute phase of rejection, but PAI-1 was upregulated and persistently expressed during the progressive phase of chronic rejection, synchronously with fibrin deposition in the grafts. They propose that induction of PAI-1 may be responsible for the fibrin deposition, which leads to irreversible damage and chronic kidney loss (18).

The chemokine receptor (CCR1), is believed to play a crucial role in the migration of leukocytes to sites of inflammation and is expressed in T cells, dendritic cells, monocytes, and occasionally in neutrophils. The chemokines and their receptors have been proposed to damage the allograft. Thus, Bedke et al (19) investigated the effects of CCR1 antagonist BX 471 in Fischer to Lewis renal transplants at Days 10, 21 and 42 after transplantation. Therapies initiated on Day 21 after transplantation reduced glomerulosclerosis and tubulointerstitial fibrosis by Day 42 after transplantation. The PAI-1 gene was downregulated, as was the transforming growth factor (TGF)- $\beta$ and others. Also, reduced collagen deposition was observed. The authors suggested that CCR1 antagonists may be a therapeutic option for fibrosis in renal grafts.

Inside the glomerulus, PAI-1 is mainly synthesized by mesangial cells. Delarue et al (20) hypothesized that thrombin, via its protease activated receptor type-1 (PAR-1) on the membrane of glomerular cells, is a mediator of PAI-1 overexpression in humans. They analyzed 23 kidney transplant patients and followed them up for up to five years. They examined mRNA expression of the PAI-1, the thrombin receptor PAR-1, among others, by reverse transcription-polymerase chain reaction. They found a significant upregulation of PAI-1 mRNA in acute rejection $(\mathrm{P}<0.05)$ in comparison with normal kidneys. A positive correlation exists between $\alpha 2$ IV collagen mRNA level and the degree of cellular infiltration. A negative correlation was found between the level of mRNA of PAR-1 and the degree of vascular thrombosis $(\mathrm{P}=0.005)$. However, a positive correlation was observed between the degradation of renal function and the mRNA level of PAI-1 $(\mathrm{P}<0.05)$. The authors concluded that glomerular PAI-1 mRNA could be predictive of long-term renal graft function.

Since PAI-1 plays an important role in renal fibrosis, Chang et al (21) examined whether serum PAI-1 has a role in predicting chronic allograft nephropathy (CAN). They examined 50 kidney transplant recipients to determine if there was a correlation between serum levels of PAI-1 and the chronic allograft damage index (CADI). They found that CADI score was associated with serum PAI-1 activity $(r=0.405, P=0.003)$ and concluded that the serum PAI-1 level may be a potential marker to predict CADI score.

The plasma level of PAI-1 is genetically determined by a homozygous polymorphism in the $4 \mathrm{G}$ allele rather than other genotypes in the promoter region. Chow et al (3) investigated if such genetic variation in the fibrinolytic system affects the long-term renal transplant outcome. One hundred and thirty patients were assessed over a period of 75 months. Baseline clinical variables were comparable among three genotype groups. There was no association between primary event and PAI-1 genotype among the entire cohort. However, they found that among subjects with prior acute rejection episodes, those homozygous for $4 \mathrm{G}$ polymorphism had a significantly higher risk of kidney rejection (3).

In a different study, 82 renal allograft recipients were investigated for the PAI-1 polymorphism. Kidney recipients with CAD had significantly lower frequencies of the $5 \mathrm{G} / 5 \mathrm{G}$ genotype and the $5 \mathrm{G}$ allele compared to those without $\mathrm{CAD}$ $(\mathrm{P}<0.001$ and $\mathrm{P}<0.05)$. The authors concluded that determination of PAI-1 genotypes prior to transplantation may help identify patients who are at risk for chronic renal transplant dysfunction (22).

Furthermore, Rerolle et al (17) determined PAI-1 genotype in over 300 donors and kidney recipients in relation to the development of fibrosis, interstitial fibrosis and tubular atrophy (IFTA). They found that donor or recipient genotype did not influence the PAI-1 plasma level in recipients. However, kidney graft survival was statistically significantly reduced in the 4G/4G (higher PAI-1 activity) donor group (107 months vs. 147.5 months, $\mathrm{P}=0.013$ ), but recipient PAI-1 genotype did not show any effects on kidney survival. The authors suggested that donor PAI-1 polymorphism impacts kidney graft survival and the donor $4 \mathrm{G} / 4 \mathrm{G}$ genotype is an independent risk factor for kidney loss as well.

Characteristic for the CAN is deposition of extracellular matrix (ECM) in all renal compartments, thus PAI-1 plays a pivotal role in ECM turnover in this condition. Rapamycin (RAPA) has been shown to improve long-term graft survival in patients with CAN and Pontrelli et al (23) investigated whether that treatment has any effect on PAI-1 gene expression. They evaluated six patients on calcineurin inhibitors (CNI) and 12 patients who received RAPA. Patients underwent a renal biopsy at time 0 (T0) and after 24 months of treatment (T24) and PAI-1 expression was evaluated by immunohistochemistry. They reported that the RAPA group exhibited a significant regression of glomerulosclerotic lesions and a modest increase in interstitial fibrosis $(26 \%)$ at T24. By contrast, CNI patients showed progress of glomerulosclerosis and a $112 \%$ increase in 
fibrosis. Immunohistochemistry showed that glomerular and tubulointerstitial PAI-1 expression was reduced in the RAPA group, but remained unchanged in the CNI patients. They concluded that RAPA reduces ECM deposition in CAN by downregulating PAI-1 expression (23).

Ishikawa et al $(24,25)$ treated kidney transplant patients with angiotensin II receptor blockers (ARB) as it is known that proteinuria from a renal graft is significantly decreased by administration of ARB. To examine the underlying mechanism, they conducted an additional clinical study to investigate changes in plasma PAI-1 levels among renal allograft recipients. Four kidney transplant patients were treated with $50 \mathrm{mg}$ /day of losartan (LOS) and four others served as a control. One year after starting the treatment, PAI-1 levels in losartan-treated patients were $78.6 \pm 6.7 \%$, while controls showed $110.4 \pm 9.2 \%$ of pretreatment levels. The authors emphasized that PAI-1 reduction by ARBs was key for renal preservation (24). In follow-up studies, they reported that patients treated with LOS immediately after transplantation had PAI-1 levels at the end of two years of treatment $81.5 \pm 10.3 \%$ of the initial PAI-1 level. A similar effect was observed in patients who started treatment two years after kidney transplantation and were observed for two additional years showing $90.1 \pm 12.5 \%$ of initial PAI-1 levels. Furthermore, microscopic examination revealed less renal interstitial fibrosis among LOS-administered groups than control groups (25).

Lahlou et al (26) investigated PAI-1 as a fibrogenic molecule whose secretion is regulated not only by genetic factors but also by several metabolic, inflammatory elements. They sought to verify if PAI-1 secretion in renal transplant patients is correlated with the decline in renal function following transplantation. One hundred and five renal transplant patients were included in the study. In addition to the routine clinical and biological data collected, the $4 \mathrm{G} / 5 \mathrm{G}$ polymorphism of the kidney transplant patient PAI-1 gene was determined, as well as the PAI-1 plasma level. The multiple linear regression analysis indicated that the rate of decline in renal function was significantly correlated with the PAI-1 plasma level $(\mathrm{P}=0.0051)$. Also, the PAI-1 plasma level was significantly correlated with body mass index $(\mathrm{P}=0.038)$, insulin $(\mathrm{P}<0.0001)$, platelet count $(\mathrm{P}<0.0001)$, and fibrinogen $(\mathrm{P}=0.024)$. However, the PAI-1 gene polymorphism did not influence the rate of decline in renal function following transplantation. The study suggests that PAI-1, whose secretion is affected by metabolic and inflammatory factors, could be related to the rate of decline in renal function after transplantation.

Revelo et al (27) analyzed renal biopsy/nephrectomy files from 82 patients and scored all cases for severity of fibrosis in vasculature (0-3 scale), glomeruli and interstitial fibrosis. They immunostained for PAI-1 and assessed on a 0-3 scale in glomeruli, vessels and tubules. PAI-1 was increased in CAN compared with non-scarred native or transplant control kidneys. The authors speculated that modified matrix metabolism can be implicated in the development of CAN.

Knowing that CAN displays extensive interstitial fibrin deposition, Grandaliano et al (28) investigated if thrombin, present within the fibrin clots, can act together with PAR-1 and modulate a variety of pathways. They investigated $16 \mathrm{CAN}$ biopsies and 10 normal human kidney grafts and found that fibrin deposits were observed in the interstitial space and arte- rial wall of CAN but not in normal grafts. Notably, PAI-1 gene expression, scarcely detectable in control tissue, was markedly increased in CAN, and showed distribution similar to the arrangement of fibrin deposition. Fibrin deposits in CAN are a result of increased expression of PAI-1 and the subsequent inhibition of UPA activity that leads to a decrease of plasmindriven fibrinolysis of ECM. Finally, thrombin preserved in the fibrin may upregulate PAR-1 and induce ECM by the TGF- $\beta$ depended pathway. They also found that urine from CAN patients contained significantly higher levels of TGF- $\beta$ (25). TGF- $\beta$ stimulates expression of PAI-1 but PAI-1 can stimulate TGF- $\beta$ expression creating positive feedback loop further promoting ECM presence (29-31).

Wang et al (32) studied PAI-1 gene expression by in situ hybridization in human renal tissue showing severe acute vascular rejection, clinically irreversible vascular rejection, mild vascular rejection, parenchymal rejection, non-rejecting kidneys and normal kidneys. They found that in $87.5 \%$ of cases showing severe acute vascular rejection and in $100 \%$ of chronic vascular rejection cases, PAI-1 mRNA was positive in endothelial cells of arterioles and arteries, and interstitial inflammatory cells but not in any other group. Notably, PAI-1 was detected frequently in areas of hemorrhage. However, it is not clear if PAI-1 caused thrombosis and ischaemia, the catastrophic consequence of severe vascular rejection or if it was produced as a response to hemorrhage in a potentially protective role.

Patrassi et al (33) used a more detailed approach in investigating fibrinolytic potential. They determined t-PA and PAI-1 activities and antigen as well as euglobulin lysis time. As measured by these determinants a hypofibrinolytic state was found in $68.4 \%$ of renal transplant patients. They concluded that an imbalance in the fibrinolytic system is a typical feature of renal transplantation patients in a long time following transplantation.

\section{PAI-1 in diabetic kidney nephropathy}

Obesity is a major risk factor for type 2 diabetes mellitus that is associated with chronic inflammation and consequential activation of the innate immune system (34). This activation results in the release of pro-inflammatory cytokines, such as tumor necrosis factor- $\alpha$ (TNF- $\alpha)$, interleukin-1 $\beta$ (IL-1 $\beta$ ) and IL-6 (35-37). These cytokines initiate the production of serum amyloid-A, haptoglobin, C-reactive protein, and PAI-1 (35). Consequently, other proteins are activated, including JNK, IKK- $\beta$ and PKC and protein tyrosine phosphatases such as PTP1B and PTEN, which impair insulin signaling at insulin receptor and insulin receptor substrate levels. Insulin resistance further stimulates the production of CRP and PAI-1 (38).

Chen et al (39) treated diabetes-induced (streptozotocin, $25 \mathrm{mg} / \mathrm{kg}$; STZ) male Wistar rats with fenofibrate, a fibrate class drug that is mainly used to reduce cholesterol levels but that also has protective effects on the diabetic kidney. The cohort included control untreated nondiabetic, untreated diabetic, and fenofibrate-treated ( $32 \mathrm{mg} / \mathrm{kg} / \mathrm{day}$, for 8 weeks) diabetic rats. Kidney nephropathies were associated with the overexpression of PAI-1 mRNA and its protein activity in the renal cortex, and a substantial raise in TGF- $\beta$. Treatment with fenofibrate lowered the expression of PAI-1 mRNA as well as 
protein activity, and inhibited TGF- $\beta$. Furthermore, partially reversed pathophysiologic changes associated with diabetic nephropathy in the treatment group were also observed. The authors emphasized that renoprotective effects were achieved through suppression of PAI- 1 and TGF- $\beta$ in the renal cortex, which reduced ECM accumulation.

Hagiwara et al (40) investigated the gene expression of fibrinolytic factors in diabetic nephropathy in the kidneys of diabetic rats. As a model of type one diabetes, they used male Sprague-Dawley rats divided into three groups: control, STZ-induced diabetic, and insulin-treated diabetic. As a model of type two diabetes, they used Otsuka Long-Evans Tokushima Fatty (OLETF) rats and as the control they used Long-Evans Tokushima Otsuka (LETO) rats. The study examined uPA, tPA and PAI-1 genes by real-time PCR. Spacial distribution of these genes was determined by in situ hybridization. In STZ-induced diabetic rats (type one diabetic model) mRNA levels were increased by $60-80 \%$ and insulin treatment reduced expression to the control level. In OLETF rats, the renal PAI-1 mRNA level was $250 \%$ of that in age-matched LETO rats. Conversely, tPA and uPA mRNA levels were lower than those in LETO rats. They found PAI-1 mRNA in intraglomerular cells and tubular epithelial cells of both models. They concluded that the PAI-1 gene was upregulated in type one and type two diabetic rats, and they suggested that modulation of gene expressions of fibrinolytic factors played a central role in the development of diabetic nephropathy.

Lee and Ha (41) used PAI-1-1 ${ }^{--}$mice and found that PAI-1 induces ECM deposition in diabetic kidneys through increased ECM synthesis by TGF- $\beta$ upregulation and through reduced ECM degradation by suppression of proteolytic activity of plasmin and MMP-2 activity. Lassila et al (42) reported that disruption of the PAI-1 gene protects mice against diabetic nephropathy in PAI-1-1- mice. Effects of PAI-1 deficiency on the renal disease in experimental diabetes in mice were also determined in another study. Diabetes was induced by injection of STZ in 6-week-old PAI-1-deficient mice, and transgenic mice overproducing PAI-1 in comparison with wild-type mice. The authors detected that the PAI-1 message was higher in kidneys from normal mice with diabetes and in nondiabetic PAI-1 transgenic mice. Diabetes-associated glomerular injury, albuminuria and, renal $\alpha$-smooth muscle actin production, were enhanced in diabetic mice in comparison with wild-type mice. Thus, they concluded that endogenous PAI-1 deficiency protects mice from glomerular injury.

A PAI-1 inhibitor may be a therapeutic agent for fibrotic diseases $(43,44)$. However, only a few PAI-1 inhibitors have been identified so far and their clinical potential has yet to be evaluated (43). Huang et al (45) overcame the shortage of PAI-1 inhibitors by short-term administration of inactive PAI-1 mutant but otherwise in active form conformation (PAI-1R). This protein slowed down the progression of glomerulosclerosis in the $\mathrm{db} / \mathrm{db}$ mice (46). They observed that PAI-1R increases glomerular plasmin generation, reverses PAI-1 inhibition of matrix degradation, and consequently reduces symptoms of disease in experimental animals. Non-treated $\mathrm{db} / \mathrm{db}$ mice used as a control developed progressive albuminuria and mesangial matrix expansion. PAI-1 in plasma binds to vitronectin (Vn) that extends PAI-1 half-life. The authors suggested that PAI-1R interferes with WT-PAI-1: Vn binding by saturating vitro- nectin with PAI-1R. Consequently, WT-PAI-1 not complexed with vitronectin converts quickly to latent form and the antiprotease activity of PAI-1 is diminished $(45,47)$.

PAI-1 levels are elevated in type two diabetes, and this elevation correlates with complications of diabetes, although the link between insulin and upregulation of PAI-1 remains unclear (48). Festa et al (49) reported the correlation between prevalence of diabetes and changes of fibrinogen and PAI-1. The duration of this study was more than 5 years and diabetes development was observed in 140 of 843 individuals. The increase of PAI-1 levels was associated with the incidence of diabetes. Furthermore, progression of PAI-1 levels over time was correlated with the development of type two diabetes as well as the rising glucose levels (49). Significant findings supporting the causative role of PAI-1 in diabetes complication were described by Nagi et al (50). An ethnic group of Pima Indians with a very high rate of obesity, insulinresistant and hyperinsulinemic, have high frequencies of diabetes as well as risk of ischemic heart disease and other diabetes complications. In contrast to other ethnic groups, PAI-1 activity is similar between nondiabetic and diabetic Pima Indians and low PAI-1 activity protects this population from side-effects.

As was observed in complications of kidney transplantation, an elevated plasma level of PAI-1 expedites diabetic vascular complications and suggests diabetic nephropathy to be the major implication of high levels of PAI-1 $(51,52)$. The PAI-1 $4 \mathrm{G}$ polymorphism is the cause of high plasma PAI-1 levels in $4 \mathrm{G}$ allele carriers suggesting that this PAI-1 polymorphism is a genetic risk factor for diabetes. Thus, Meigs et al (52) tested this hypothesis among 2,169 participants. They concluded that elevated PAI-1 levels may indeed be associated with an increased risk for diabetes and endothelial dysfunction in these patients.

\section{PAI-1 in chronic kidney disease}

Defined as estimated glomerular filtration rate (eGFR) $<60 \mathrm{ml} /$ $\min / 1.73 \mathrm{~m}^{2}$, chronic kidney disease (CKD) is an increasing medical problem. In the US, approximately 26 million people have CKD (53). Of the diseases leading to CKD, chronic glomerulonephritis, diabetes mellitus, hypertension, ischemia and urological obstruction contribute to renal fibrosis. A reduced glomerular filtration rate may lead to endothelial dysfunction and inflammatory activity, which can be detected by measurement of the biochemical markers which have been shown to predict CV disease. An impaired renal function is associated with the markers of endothelial dysfunction and increased inflammatory activity (54). The endothelial dysfunction links the processes of immune inflammation, hemorheology and fibrinolysis/proteolysis in the kidney (55). Also, recent epidemiological studies linked CKD with a risk of venous thrombosis directly related to increased levels of PAI-1 (56).

Several possible mechanisms explain the association of low eGFR and higher levels of the hemostatic factors. Decreased renal clearance may cause an increase in the levels of smaller molecular weight hemostatic markers. On the other hand, kidney dysfunction may generate a thrombotic milieu indirectly through the electrolyte or acid-base abnormalities, 
which may alter activities of enzymes involved in coagulation (57). CKD stage 3 to 5 is an established risk factor for CV morbidity and mortality although the mechanisms underlying the association are not fully understood (58). This association begins in the preclinical stages of kidney disease (57). Several studies indicated that atherosclerosis and the increased risk of $\mathrm{CV}$ disease are associated with inflammation and coagulation (59). The relation between chronic inflammation and CKD are better documented, but deregulation of hemostasis contributing to the association of CKD and CVD has yet to be fully examined. Results of a study by Dubin et al (57) indicated that patients with eGFR $<60 \mathrm{ml} / \mathrm{min} / 1.73 \mathrm{~m}^{2}$ presented PAI-1 at $6.5 \%$ higher levels compared to subjects with eGFR $>90$. The study suggested that the deregulation of hemostasis may play an important pathologic role in CKD.

\section{Hemodialysis (HD) and PAI-1}

CKD (stage 5) patients face a more than 3-fold higher risk of $\mathrm{CV}$ events compared with the general population, and the chronic hemodialysis (CHD) patients face a 100-fold higher risk of $\mathrm{CV}$ mortality compared with the general population of patients aged $\leq 45$ years. Traditional risk factors for atherosclerosis do not account for the increased incidence of the $\mathrm{CV}$ events. On the other hand, biomarkers of the oxidative stress and inflammation can predict $\mathrm{CV}$ events in CHD patients (60).

During HD, contact of the blood with the dialyzer and dialysate activates the kallikrein-kinin system (KKS) and induces a systemic inflammatory response characterized by the leukocyte activation, and generation of cytokines. For example, HD increases leukocyte expression of IL-1 $\beta$, IL-8 and TNF- $\alpha$, and the circulating concentrations of IL-6 (61). Increased inflammation may, in turn, contribute to imbalances in the fibrinolytic system in CHD patients. Cytokines such as TNF- $\alpha$, IL-1 $\beta$ and IL- 6 stimulate expression of PAI-1, the major physiologic inhibitor of fibrinolysis in vivo. t-PA concentrations and activity increase transiently during HD, whereas circulating PAI-1 concentrations are increased in the CHD population (62). It has been shown that dialysis patients treated by HD or peritoneal dialysis (PD) have increased plasma levels of PAI-1 which makes them vulnerable to CV risk (63). CHD patients exhibit abnormalities in the platelet function, fibrinolysis and coagulation (60). Fibrinolytic activity increases acutely during HD, largely related to the increase in t-PA, but decreases markedly after HD (64). Some investigators have reported no change in PAI-1 antigen or activity during HD, but have not measured PAI-1 in the postdialysis period. Marney et al (60) observed increased PAI-1 after dialysis. In their study, they showed that bradykinin $\mathrm{B}_{2}$ receptor blockade abolished the increase in PAI-1 following HD, suggesting that the CHD patients exhibit endothelial dysfunction and that the pro-inflammatory effects of bradykinin predominates in regulating PAI-1, at least during HD. PAI-1 antigen is both an acute-phase reactant and an inhibitor of fibrinolysis. During HD, increased t-PA antigen may complex with PAI-1 antigen causing a decrease in its activity. The data from Marney et al (60) suggested that endogenous bradykinin receptor blockade attenuates fibrinolysis.
In agreement with previous observations (65), Stefoni et al (66) reported that PAI-1 values in hemodialyzed patients proved higher than among controls. The increase was more noticeable in cardiovascular HD patients. These results may be related to the high plasma cytokine levels found in hemodialyzed patients and related to the degree of endothelium dysfunction. In the study by Stefoni et al (66), PAI-1 levels showed a moderate, inverse correlation with TGF-1 levels. This effect may combine with the similar inhibition by Lp(a) (lipoprotein) and partly explain the low TGF-1 values.

The study of Segarra et al (62) consisted of $200 \mathrm{HD}$ patients and investigated the relationship between the circulating levels of the endothelial cell glycoproteins, PAI-1, tPA, thrombomodulin and the major vascular risk factors described in dialysis patients, and determined the role of these endothelial cell products as independent predictors of atheromatous cardiovascular disease in a large group of nondiabetic dialysis patients. This study concluded that circulating PAI-1 was an independent predictor of complications in coronary artery stenosis after adjusting for the major vascular risk factors and CRP. Collectively, our data suggest that increased circulating PAI-1 could indicate a chronic endothelium activated state and could be used as an additional tool in identifying dialysis patients who are at risk for developing atheromatous $\mathrm{CV}$ disease.

\section{Peritoneal dialysis (PD) and PAI-1}

Kim et al (67) reported that PD patients with atherosclerosis had significantly higher tPA levels than those without atherosclerosis and the normal controls. An elevated tPA antigen level in patients with atherosclerotic vascular disease reflects primarily an increase in circulating complexes of tPA and PAI-1, which can explain a positive correlation between tPA and PAI-1 levels. Several longitudinal cohort studies have also provided evidence that impaired fibrinolysis due to increased PAI-l activity is implicated in the pathogenesis of atherosclerotic disease. PD patients with atherosclerosis had significantly higher PAI-l levels than those without atherosclerosis and the normal controls. Kim et al (67) observed correlations between PAI-1 and triglycerides, which were also reported by Gray et al (68). These findings suggest that fibrinolytic activity is correlated with lipid disturbances.

Arikan et al (63) investigated whether PAI-1 could independently predict CV outcome in PD patients. They studied 72 PD patients and in a multivariable Cox regression analysis showed that plasma PAI-1 at $41 \mathrm{ng} / \mathrm{ml}$ was independently predictive of higher $\mathrm{CV}$ mortality $(\mathrm{P}=0.021)$ and $\mathrm{CV}$ events $(\mathrm{CVEs})(\mathrm{P}=0.001)$. The only other independent predictor of $\mathrm{CV}$ mortality was CRP ( $5 \mathrm{mg} / \mathrm{l} ; \mathrm{P}=0.008)$. The authors suggested that plasma levels of PAI-1 $>41 \mathrm{ng} / \mathrm{ml}$ are a significant predictor of CV mortality and CVEs in PD patients.

Pawlak et al (69) showed that PD patients had high concentrations of PAI-1 and that tissue factor (TF), its inhibitor (TFPI), prothrombin fragment $1+2[\mathrm{~F}(1+2)]$, uPA, its soluble receptor (suPAR), plasmin/antiplasmin (PAP) complexes, KYN, kynurenic (KYNA) and quinolinic (QA) acid levels were significantly higher as well. Tissue-type plasminogen activator and PAI-1 were higher in patients with CVD compared to patients without CVD and normal controls. 
Malyszko et al (70) indicated that adipose tissue secretes various bioactive substances including leptin, TNF, adiponectin and PAI-1 and may contribute to the CVD in the PD patients. PAI-1 is closely involved in the development of atherosclerosis. In PD patients prone to atherosclerosis and $\mathrm{CV}$ complications, adiponectin was inversely related to PAI-1 in both diabetic and nondiabetic peritoneally dialyzed subjects. Maruyoshi et al (71) reported a similar correlation in patients with a stable angina. Moreover, in a multiple regression analysis, in addition to gender and angina pectoris, PAI-1 was an independent determinant of a hyperadiponectinemia. In the study by Malyszko et al (70), PAI-1 was higher and adiponectin was lower in the PD patients with CVD, compared to the patients without CVD. However, in the patients with CVD, correlation between adiponectin and PAI-1 did not reach statistical significance $(r=-0.51$, $\mathrm{P}=0.084)$. Correlation between PAI-1 and adiponectin in the PD patients (both diabetic and nondiabetic) may support the hypothesis that adiponectin acts as a protective factor for the CV system.

An additional role of PAI-1 was reported by Lin et al (72), who described that PAI-1 measured during PD may reflect the intraperitoneal fibrinolytic balance. Elevated PAI-1 levels observed during PD may impede peritoneal solute and water transport by its maintenance and enhanced deposition of basement membranes and peritoneal interstitial ECM. They suggested that intraperitoneal plasminogen activators may be of therapeutic clinical value in such PD patients with elevated PAI-1 levels and altered peritoneal transport. Lin et al (72) observed a correlation between dialysate PAI-1 levels and the episodes of peritonitis, and concluded that the elevated PAI-1 levels in dialysate were likely from the local production and release of PAI-1. Also, repeated inflammation of the peritoneum was associated with an increased production and release of PAI-1 into the peritoneum.

\section{Conclusions}

A delicate balance exists between ECM synthesis and degradation that is regulated largely by PAI-1. Increased PAI-1 expression results in accumulation of ECM leading to numerous kidney diseases. Predisposition to some diseases is due to the genetic role of PAI-1 in their development (73).

Several studies have demonstrated that inhibition of PAI-1 activity or therapy with a mutant PAI-1 increases matrix turnover and reduces glomerulosclerosis by competing with endogenous PAI-1, strongly suggesting that PAI-1 is a valid target in the treatment of fibrotic renal disease. However, net proteolytic activity depends on the delicate balance between its negative regulation by PAI- 1 and activation by uPA and tPA. Also, plasmin activated by its inhibitors upregulates the activity of other proteolytic enzymes such as collagenases and metalloproteinases $(13,74,75)$. Thus, assessment of prognosis for the diseased kidney should include a variety of proteolysis regulators and enzymes.

Other than its protease inhibitory activity, the de-adhesive action of PAI-1 is less understood and plays an unknown role in kidney disease $(76,77)$. Additional not proteolytic activity of PAI-1 includes upregulating TGF- $\beta$ which in positive feedback promotes synthesis of PAI-1 (44,78-83).
Thus, TGF- $\beta$ may be the therapeutic target in nephropathy moderating ECM production through the PAI-1 pathway $(44,84-87)$.

\section{References}

1. Buduneli N, Buduneli E, Ciotanar S, Atilla G, Lappin D and Kinane D: Plasminogen activators and plasminogen activator inhibitors in gingival crevicular fluid of cyclosporin A-treated patients. J Clin Periodontol 31: 556-561, 2004.

2. Chorostowska-Wynimko J, Swiercz R, Skrzypczak-Jankun E, Wojtowicz A, Selman SH and Jankun J: A novel form of the plasminogen activator inhibitor created by cysteine mutations extends its half-life: relevance to cancer and angiogenesis. Mol Cancer Ther 2: 19-28, 2003.

3. Chow KM, Szeto CC, Szeto CY, Poon P, Lai FM and Li PK: Plasminogen activator inhibitor-1 polymorphism is associated with progressive renal dysfunction after acute rejection in renal transplant recipients. Transplantation 74: 1791-1794, 2002.

4. Fay WP, Parker AC, Condrey LR and Shapiro AD: Human plasminogen activator inhibitor-1 (PAI-1) deficiency: characterization of a large kindred with a null mutation in the PAI-1 gene. Blood 90: 204-208, 1997.

5. Jankun J, Aleem AM, Struniawski R, Lysiak-Szydlowska W, Selman SH and Skrzypczak-Jankun E: Accelerated thrombus lysis in the blood of plasminogen activator inhibitor deficient mice is inhibited by PAI-1 with a very long half-life. Pharmacol Rep 61: 673-680, 2009.

6. Zhu Y, Carmeliet P and Fay WP: Plasminogen activator inhibitor-1 is a major determinant of arterial thrombolysis resistance. Circulation 99: 3050-3055, 1999.

7. Lopes C, Dina C, Durand E and Froguel P: PAI-1 polymorphisms modulate phenotypes associated with the metabolic syndrome in obese and diabetic Caucasian population. Diabetologia 46: 1284-1290, 2003.

8. Babu MS, Prabha TS, Kaul S, et al: Association of genetic variants of fibrinolytic system with stroke and stroke subtypes. Gene 495: 76-80, 2012.

9. Jood K, Ladenvall P, Tjarnlund-Wolf A, et al: Fibrinolytic gene polymorphism and ischemic stroke. Stroke 36: 2077-2081, 2005.

10. Wiklund PG, Nilsson L, Ardnor SN, et al: Plasminogen activator inhibitor-1 $4 \mathrm{G} / 5 \mathrm{G}$ polymorphism and risk of stroke: replicated findings in two nested case-control studies based on independent cohorts. Stroke 36: 1661-1665, 2005.

11. Ringelstein M, Jung A, Berger K, et al: Promotor polymorphisms of plasminogen activator inhibitor-1 and other thrombophilic genotypes in cerebral venous thrombosis: a case-control study in adults. J Neurol: Apr 12, 2012 (Epub ahead of print).

12. Jankun J, Aleem AM, Selman SH, Basrur V and SkrzypczakJankun E: VLHL plasminogen activator inhibitor spontaneously reactivates from the latent to active form. Int J Mol Med 23: 57-63, 2009.

13. Jankun J and Skrzypczak-Jankun E: Yin and yang of the plasminogen activator inhibitor. Pol Arch Med Wewn 119: 410-417, 2009.

14. Lim JH, Stirling B, Derry J, et al: Tumor suppressor CYLD regulates acute lung injury in lethal Streptococcus pneumoniae infections. Immunity 27: 349-360, 2007.

15. Eddy AA and Fogo AB: Plasminogen activator inhibitor-1 in chronic kidney disease: evidence and mechanisms of action. J Am Soc Nephrol 17: 2999-3012, 2006.

16. Lottermoser K, Petras S, Poge U, et al: The fibrinolytic system in chronic renal failure. Eur J Med Res 6: 372-376, 2001.

17. Rerolle JP, Munteanu E, Drouet M, et al: PAI-1 donor polymorphism influences long-term kidney graft survival. Nephrol Dial Transplant 23: 3325-3332, 2008.

18. Wang Y, Pratt JR, Hartley B, Evans B, Zhang L and Sacks SH: Expression of tissue type plasminogen activator and type 1 plasminogen activator inhibitor, and persistent fibrin deposition in chronic renal allograft failure. Kidney Int 52: 371-377, 1997.

19. Bedke J, Kiss E, Schaefer L, et al: Beneficial effects of CCR1 blockade on the progression of chronic renal allograft damage. Am J Transplant 7: 527-537, 2007.

20. Delarue F, Hertig A, Alberti C, et al: Prognostic value of plasminogen activator inhibitor type 1 mRNA in microdissected glomeruli from transplanted kidneys. Transplantation 72: 1256-1261, 2001 
21. Chang HR, Yang SF, Lian JD, et al: Prediction of chronic allograft damage index of renal allografts using serum level of plasminogen activator inhibitor-1. Clin Transplant 23: 206-212, 2009.

22. Reis K, Arinsoy T, Derici U, et al: Angiotensinogen and plasminogen activator inhibitor-1 gene polymorphism in relation to chronic allograft dysfunction. Clin Transplant 19: 10-14, 2005

23. Pontrelli $\mathrm{P}$, Rossini $\mathrm{M}$, Infante $\mathrm{B}$, et al: Rapamycin inhibits PAI-1 expression and reduces interstitial fibrosis and glomerulosclerosis in chronic allograft nephropathy. Transplantation 85 : 125-134, 2008.

24. Ishikawa A, Ohta N, Ozono S, Kawabe $\mathrm{K}$ and Kitamura T: Inhibition of plasminogen activator inhibitor-1 by angiotensin II receptor blockers on cyclosporine-treated renal allograft recipients. Transplant Proc 37: 994-996, 2005.

25. Ishikawa A, Tanaka M, Ohta N, Ozono S and Kitamura T: Prevention of interstitial fibrosis of renal allograft by angiotensin II blockade. Transplant Proc 38: 3498-3501, 2006.

26. Lahlou A, Peraldi MN, Thervet E, et al: Chronic graft dysfunction in renal transplant patients: potential role of plasminogen activator inhibitor type 1. Transplantation 73: 1290-1295, 2002.

27. Revelo MP, Federspiel C, Helderman H and Fogo AB: Chronic allograft nephropathy: expression and localization of PAI-1 and PPAR-gamma. Nephrol Dial Transplant 20: 2812-2819, 2005.

28. Grandaliano G, Di Paolo S, Monno R, et al: Protease-activated receptor 1 and plasminogen activator inhibitor 1 expression in chronic allograft nephropathy: the role of coagulation and fibrinolysis in renal graft fibrosis. Transplantation 72: 1437-1443, 2001.

29. Alessi MC, Bastelica D, Morange P, et al: Plasminogen activator inhibitor 1, transforming growth factor-beta1, and BMI are closely associated in human adipose tissue during morbid obesity. Diabetes 49: 1374-1380, 2000.

30. Brown NJ: Therapeutic potential of plasminogen activator inhibitor-1 inhibitors. Ther Adv Cardiovasc Dis 4: 315-324, 2010.

31. Grant PJ: Diabetes mellitus as a prothrombotic condition. J Intern Med 262: 157-172, 2007.

32. Wang Y, Thompson EM, Whawell SA and Fleming KA: Expression and localization of plasminogen activator inhibitor 1 mRNA in transplant kidneys. J Pathol 169: 445-450, 1993.

33. Patrassi GM, Sartori MT, Rigotti P, et al: Reduced fibrinolytic potential one year after kidney transplantation. Relationship to long-term steroid treatment. Transplantation 59: 1416-1420, 1995.

34. Jankun J, Skotnicka M, Lysiak-Szydlowska W, Al-Senaidy A and Skrzypczak-Jankun E: Diverse inhibition of plasminogen activator inhibitor type 1 by theaflavins of black tea. Int $\mathrm{J}$ Mol Med 27: 525-529, 2011.

35. Badawi A, Klip A, Haddad P, et al: Type 2 diabetes mellitus and inflammation: Prospects for biomarkers of risk and nutritional intervention. Diabetes Metab Syndr Obes 3: 173-186, 2010

36. Birgel M, Gottschling-Zeller H, Rohrig K and Hauner H: Role of cytokines in the regulation of plasminogen activator inhibitor-1 expression and secretion in newly differentiated subcutaneous human adipocytes. Arterioscler Thromb Vasc Biol 20: 1682-1687, 2000.

37. Samad F and Loskutoff DJ: The fat mouse: a powerful genetic model to study elevated plasminogen activator inhibitor 1 in obesity/NIDDM. Thromb Haemost 78: 652-655, 1997.

38. Meshkani R and Adeli K: Hepatic insulin resistance, metabolic syndrome and cardiovascular disease. Clin Biochem 42: 1331-1346, 2009.

39. Chen LL, Zhang JY and Wang BP: Renoprotective effects of fenofibrate in diabetic rats are achieved by suppressing kidney plasminogen activator inhibitor-1. Vascul Pharmacol 44: 309-315, 2006.

40. Hagiwara H, Kaizu K, Uriu K, et al: Expression of type-1 plasminogen activator inhibitor in the kidney of diabetic rat models Thromb Res 111: 301-309, 2003.

41. Lee HB and Ha H: Plasminogen activator inhibitor-1 and diabetic nephropathy. Nephrology (Carlton) 10 (Suppl): S11-S13, 2005.

42. Lassila M, Fukami K, Jandeleit-Dahm K, et al: Plasminogen activator inhibitor-1 production is pathogenetic in experimental murine diabetic renal disease. Diabetologia 50: 1315-1326, 2007.

43. Miyata T and van Ypersele de Strihou C: Translation of basic science into clinical medicine: novel targets for diabetic nephropathy. Nephrol Dial Transplant 24: 1373-1377, 2009.

44. Nicholas SB, Aguiniga E, Ren Y, et al: Plasminogen activator inhibitor-1 deficiency retards diabetic nephropathy. Kidney Int 67: 1297-1307, 2005.
45. Huang Y, Border WA, Lawrence DA and Noble NA: Mechanisms underlying the antifibrotic properties of noninhibitory PAI-1 (PAI-1R) in experimental nephritis. Am J Physiol Renal Physiol 297: F1045-F1054, 2009.

46. Oh KS, Kim EY, Yoon M and Lee CM: Swim training improves leptin receptor deficiency-induced obesity and lipid disorder by activating uncoupling proteins. Exp Mol Med 39: 385-394, 2007

47. Huang Y, Border WA, Yu L, Zhang J, Lawrence DA and Noble NA: A PAI-1 mutant, PAI-1R, slows progression of diabetic nephropathy. J Am Soc Nephrol 19: 329-338, 2008.

48. Ho CH and Jap TS: Relationship of plasminogen activator inhibitor-1 with plasma insulin, glucose, triglyceride and cholesterol in Chinese patients with diabetes. Thromb Res 69: 271-277, 1993.

49. Festa A, Williams K, Tracy RP, Wagenknecht LE and Haffner SM Progression of plasminogen activator inhibitor-1 and fibrinogen levels in relation to incident type 2 diabetes. Circulation 113: 1753-1759, 2006

50. Nagi DK, Tracy R and Pratley R: Relationship of hepatic and peripheral insulin resistance with plasminogen activator inhibitor-1 in Pima Indians. Metabolism 45: 1243-1247, 1996.

51. Collins SJ, Alexander SL, Lopez-Guisa JM, et al: Plasminogen activator inhibitor-1 deficiency has renal benefits but some adverse systemic consequences in diabetic mice. Nephron Exp Nephrol 104: e23-e34, 2006.

52. Meigs JB, Dupuis J, Liu C, et al: PAI-1 Gene 4G/5G polymorphism and risk of type 2 diabetes in a population-based sample. Obesity (Silver Spring) 14: 753-758, 2006.

53. Samarakoon R, Overstreet JM, Higgins SP and Higgins PJ: TGF- $\beta 1$ $\rightarrow \mathrm{SMAD} / \mathrm{p} 53 / \mathrm{USF} 2 \rightarrow \mathrm{PAI}-1$ transcriptional axis in ureteral obstruction-induced renal fibrosis. Cell Tissue Res 347: 117-128, 2012.

54. Stam F, van Guldener C, Schalkwijk CG, ter Wee PM, Donker AJ and Stehouwer CD: Impaired renal function is associated with markers of endothelial dysfunction and increased inflammatory activity. Nephrol Dial Transplant 18: 892-898, 2003.

55. Smyr KV, Shcherbak AV, Kozlovskaia LV, Sokolova IA, Bobkova IN and Podorolskaia LV: Significance of the markers of endothelial dysfunction and hemorheological disorders for assessing the activity and prognosis of chronic glomerulonephritis. Ter Arkh 82: 47-51, 2010 (In Russian).

56. Folsom AR, Delaney JA, Lutsey PL, et al: Associations of factor VIIIc, D-dimer, and plasmin-antiplasmin with incident cardiovascular disease and all-cause mortality. Am J Hematol 84: 349-353, 2009.

57. Dubin R, Cushman M, Folsom AR, et al: Kidney function and multiple hemostatic markers: cross sectional associations in the multi-ethnic study of atherosclerosis. BMC Nephrol 12: 3 , 2011.

58. Coresh J, Astor B and Sarnak MJ: Evidence for increased cardiovascular disease risk in patients with chronic kidney disease. Curr Opin Nephrol Hypertens 13: 73-81, 2004.

59. Hellenthal FA, Buurman WA, Wodzig WK and Schurink GW: Biomarkers of AAA progression. Part 1: extracellular matrix degeneration. Nat Rev Cardiol 6: 464-474, 2009.

60. Marney AM, Ma J, Luther JM, Ikizler TA and Brown NJ Endogenous bradykinin contributes to increased plasminogen activator inhibitor 1 antigen following hemodialysis. J Am Soc Nephrol 20: 2246-2252, 2009.

61. Horl WH: Hemodialysis membranes: interleukins, biocompatibility, and middle molecules. J Am Soc Nephrol 13 (Suppl 1): S62-S71, 2002.

62. Segarra A, Chacon P, Martinez-Eyarre C, et al: Circulating levels of plasminogen activator inhibitor type-1, tissue plasminogen activator, and thrombomodulin in hemodialysis patients: biochemical correlations and role as independent predictors of coronary artery stenosis. J Am Soc Nephrol 12: 1255-1263, 2001.

63. Arikan H, Koc M, Tuglular S, Ozener C and Akoglu E: Elevated plasma levels of PAI-1 predict cardiovascular events and cardiovascular mortality in prevalent peritoneal dialysis patients. Ren Fail 31: 438-445, 2009.

64. Nakamura Y, Tomura S, Tachibana K, Chida Y and Marumo F: Enhanced fibrinolytic activity during the course of hemodialysis. Clin Nephrol 38: 90-96, 1992.

65. Kunz K, Petitjean P, Lisri M, et al: Cardiovascular morbidity and endothelial dysfunction in chronic haemodialysis patients: is homocyst(e)ine the missing link? Nephrol Dial Transplant 14 1934-1942, 1999.

66. Stefoni S, Cianciolo G, Donati G, et al: Low TGF-beta1 serum levels are a risk factor for atherosclerosis disease in ESRD patients. Kidney Int 61: 324-335, 2002. 
67. Kim KJ, Yang WS, Kim SB, Lee SK and Park JS: Fibrinogen and fibrinolytic activity in CAPD patients with atherosclerosis and its correlation with serum albumin. Perit Dial Int 17: 157-161, 1997.

68. Gray RP, Mohamed-Ali V, Patterson DL and Yudkin JS: Determinants of plasminogen activator inhibitor-1 activity in survivors of myocardial infarction. Thromb Haemost 73: 261-267, 1995.

69. Pawlak K, Mysliwiec M and Pawlak D: Haemostatic system, biochemical profiles, kynurenines and the prevalence of cardiovascular disease in peritoneally dialyzed patients. Thromb Res 125: 40-45, 2010.

70. Malyszko J, Malyszko JS, Brzosko S, Wolczynski S and Mysliwiec M: Adiponectin is related to CD146, a novel marker of endothelial cell activation/injury in chronic renal failure and peritoneally dialyzed patients. J Clin Endocrinol Metab 89: 4620-4627, 2004.

71. Maruyoshi H, Kojima S, Funahashi T, et al: Adiponectin is inversely related to plasminogen activator inhibitor type 1 in patients with stable exertional angina. Thromb Haemost 91: 1026-1030, 2004.

72. Lin JJ, Singhal K, Parton L, Cascio C, Patlak CS and Stewart CL: Correlations between plasminogen activator inhibitor-1 and peritoneal transport in pediatric CCPD patients. Perit Dial Int 15 : 246-251, 1995.

73. Chang HR, Yang SF, Tsai JP, et al: Plasminogen activator inhibitor- $15 \mathrm{G} / 5 \mathrm{G}$ genotype is a protecting factor preventing posttransplant diabetes mellitus. Clin Chim Acta 412: 322-326, 2011.

74. Gao MJ, Liu M, Li B, Li ML, Bian LX and Yu GN: Protective effect of calcium dobesilate against early diabetic nephropathy of rat kidney. Yao Xue Xue Bao 44: 126-133, 2009 (In Chinese).

75. Qi W, Poronnik P, Young B, Jackson CJ, Field MJ and Pollock CA: Human cortical fibroblast responses to high glucose and hypoxia. Nephron Physiol 96: 121-129, 2004.

76. Czekay RP, Aertgeerts K, Curriden SA and Loskutoff DJ: Plasminogen activator inhibitor-1 detaches cells from extracellular matrices by inactivating integrins. J Cell Biol 160: 781-791, 2003.

77. Jankun J, Aleem AM, Specht Z, et al: PAI-1 induces cell detachment, downregulates nucleophosmin (B23) and fortilin (TCTP) in LnCAP prostate cancer cells. Int J Mol Med 20: 11-20, 2007.
78. Guo B, Inoki K, Isono M, et al: MAPK/AP-1-dependent regulation of PAI-1 gene expression by TGF-beta in rat mesangial cells. Kidney Int 68: 972-984, 2005.

79. Huang W, Xu C, Kahng KW, Noble NA, Border WA and Huang Y: Aldosterone and TGF-betal synergistically increase PAI-1 and decrease matrix degradation in rat renal mesangial and fibroblast cells. Am J Physiol Renal Physiol 294: F1287-F1295, 2008.

80. Ma J, Weisberg A, Griffin JP, Vaughan DE, Fogo AB and Brown NJ: Plasminogen activator inhibitor-1 deficiency protects against aldosterone-induced glomerular injury. Kidney Int 69: 1064-1072, 2006

81. Ma LJ, Yang H, Gaspert A, et al: Transforming growth factor-beta-dependent and -independent pathways of induction of tubulointerstitial fibrosis in beta6(-/-) mice. Am J Pathol 163: 1261-1273, 2003.

82. Song CY, Kim BC, Hong HK and Lee HS: TGF-beta type II receptor deficiency prevents renal injury via decrease in ERK activity in crescentic glomerulonephritis. Kidney Int 71: 882-888, 2007.

83. Tesch GH and Lim AK: Recent insights into diabetic renal injury from the $\mathrm{db} / \mathrm{db}$ mouse model of type 2 diabetic nephropathy. Am J Physiol Renal Physiol 300: F301-F310, 2011.

84. Choudhury D, Tuncel M and Levi M: Diabetic nephropathy - a multifaceted target of new therapies. Discov Med 10: 406-415, 2010.

85. Guney I, Selcuk NY, Altintepe L, Atalay H, Basarali MK and Buyukbas S: Antifibrotic effects of aldosterone receptor blocker (spironolactone) in patients with chronic kidney disease. Ren Fail 31: 779-784, 2009.

86. Peters H, Border WA and Noble NA: Targeting TGF-beta overexpression in renal disease: maximizing the antifibrotic action of angiotensin II blockade. Kidney Int 54: 1570-1580, 1998.

87. Yu L, Border WA, Anderson I, McCourt M, Huang Y and Noble NA: Combining TGF-beta inhibition and angiotensin II blockade results in enhanced antifibrotic effect. Kidney Int 66: 1774-1784, 2004. 